\title{
FUTEBOL NO BRASIL: ORIGEM E EVOLUÇÃO DAS METODOLOGIAS DE TREINAMENTO
}

\section{ARTIGO DE REVISÃO}

FERRARI, Cássio Luiz ${ }^{1}$

FERRARI, Cássio Luiz. Futebol no Brasil: Origem e evolução das metodologias de treinamento. Revista Científica Multidisciplinar Núcleo do Conhecimento. Ano 05, Ed. 09, Vol. 08, pp. 79-98. Setembro de 2020. ISSN: 2448-0959, Link de acesso: https://www.nucleodoconhecimento.com.br/educacao-fisica/futebol-no-brasil

\section{RESUMO}

O futebol tem se caracterizado ao longo da história como um fenômeno esportivo que envolve e mobiliza milhões de pessoas por todo mundo, gerando empregos diretos e indiretos se transformando, portanto, em um grande produto de comercialização e consumo por seus apaixonados torcedores. O objetivo deste trabalho é verificar a origem do futebol no Brasil, e as tendências de treinamento que surgiram ao longo da história, buscando novos horizontes para operacionalização do processo de treino no futebol. Foi realizada uma pesquisa bibliográfica na literatura especializada em mecanismos de pesquisa como Scielo, Google Acadêmico, além de periódicos especializados, e livros em português. Em que pese, possam existir controvérsias, a Football Association definiu que Charles Miller foi quem trouxe o futebol para o Brasil, tendo depois difundido o esporte e quem realmente conhecia as regras do futebol. Quanto às tendências de treinamento ao longo da história, parece ser a periodização tática, a que mais apresenta pressupostos teóricos que contemplam a especificidade que o futebol necessita, para implantação do modelo de jogo a partir do processo de operacionalização do treino, através dos princípios de jogo. Entendemos que o assunto é inesgotável na área, e novos estudos devem ser feitos a fim de proporcionar

1 Pós Graduado em Educação Física Escolar; Pós graduado em Treinamento Desportivo e Personal Trainer; Licenciatura Plena. 
maiores conhecimentos a respeito da origem do futebol e sua evolução do treinamento.

Palavra-chave: Futebol, história do futebol, treinamento tático.

\section{INTRODUÇÃO}

Com a chegada do futebol ao Brasil, foi grande a adesão pelo esporte, assumindo importante protagonismo com a prática coletiva que logo fazia parte da rotina nas escolas e da população pela facilidade de ser praticado, proporcionando alegria, integração e qualidade de vida aos praticantes, vindo mais tarde a ser o esporte mais difundido no país sem dúvida.

O futebol está inserido como elemento cultural do povo brasileiro, fazendo parte do calendário de realizações esportivas, no qual teve como grande incentivador Charles Willian Miller que em 1.894 retornou dos seus estudos na Inglaterra com uma bola, uniformes e o livro de regras, ficando oficialmente definido como o ano do surgimento do futebol no Brasil. (OLIVEIRA; COLPAS, 2014).

Depois do surgimento do futebol no Brasil, em que houve grande adesão da população brasileira, no qual se caracteriza por um fenômeno mundial e complexo, mobilizando milhões de pessoas em todo o mundo, parece haver uma constante evolução nos processos de treinamento.

Verificamos ao longo da história uma grande evolução, no futebol com quebra de paradigmas e novos conceitos que surgiram com a ciência esportiva trabalhando de forma multidisciplinar, Leitão (2009), entende que a preparação deve estar condicionada a forma de jogar de acordo com o modelo concebido pelo treinador, e que é provável que diferentes tendências de treinamento é concebido em diversas regiões do mundo

Nesse contexto, as tendências de treinamento e a evolução da preparação física, contribuíram com o desenvolvimento das metodologias de treinamento no futebol, 
apresentando assim, aumento no desempenho, e melhores resultados em competições.

\section{OBJETIVOS}

Verificar a origem do futebol no Brasil.

Verificar as tendências de treinamento que surgiram até os dias de hoje e suas contribuições.

\section{REFERENCIAL TEÓRICO}

\section{CRONOLOGIA DO SURGIMENTO DO FUTEBOL NO BRASIL}

1746- Existem registros, que algo parecido com uma atividade esportiva, já era praticado com uma bola no Brasil, nesse sentido, Aquino, Oliveira e Coplas, (2014), afirmam que havia uma atividade esportiva praticada na Câmara Municipal de São Paulo, mas que era proibida por que gerava aglomeração de pessoas desocupadas, não evidenciando de fato a característica do jogo em questão.

1.864- Fortes evidências sugerem que os primeiros jogos ou atividades parecidas com futebol, segundo Voser, Guimarães e Ribeiro (2006), tenham sido realizadas pelos ingleses e holandeses, tripulantes de navios que atracavam no litoral nordestino e praticavam a atividade com os moradores locais

1.872- Há relatos ainda, de práticas com características de um jogo com bola, que acontecia na província de São Paulo no Colégio São Luís, no interior de São Paulo na cidade de Itu. O grande incentivador para as práticas esportivas dos alunos no colégio, eram feitas pelo sacerdote da comunidade que orientava a chutarem uma bola de couro contra os muros que delimitavam a dependência do colégio. (OLIVEIRA; COLPAS, 2014). 
1.875 - Entretanto, há controvérsias para a época uma vez que Vosear, Guimarães e Ribeiro, (2006), conforme indicam achados, que teria sido Mr. John, em São Paulo quem realmente teria introduzido o futebol no Brasil.

1.882 - Voser, Guimarães e Ribeiro, (2006), reiteram ainda, que Mr Hugs, também teria ensinado na época, trabalhadores em Jundiaí a praticar a modalidade de futebol.

1.892 - Oficialmente, o único registro do termo "futebol" só foi encontrado em um fragmento citado no Regulamento do Colégio Pedro II, no Rio de Janeiro. (OLIVEIRA; COLPAS, 2014).

Oliveira e Colpas, (2014), destacam que existem fortes evidências que em 1894 Charles Willian Miller, foi quem realmente trouxe o futebol para o Brasil, pois conhecia as regras, trouxe consigo uma bola de couro, além do fardamento para a prática esportiva que iniciou na capital paulista.

Entretanto, alguns achados na literatura apontam controvérsias quanto ao surgimento do futebol no Brasil, uma vez que Miller deixou o material esquecido em um armário desde a sua chegada ao País, em 09 de junho de 1.894, até 14 de abril de 1.895, o que sugere que Miller não teria a intenção de difundir o esporte no Brasil. (VOSER; GUIMARÃES; RIBEIRO, 2006).

De acordo com Voser; Guimarães; Ribeiro (2006), existem fortes evidências que o brasileiro Charles Miller, ao ir para Inglaterra com 10 anos de idade, para estudar na escola Court Scool em Southampton, adepta, a The Football Asociation, conheceu o futebol e as regras e suas regras, tendo anos mais tarde, retornado para o Brasil difundido o esporte.

A literatura aponta ainda conforme Voser; Guimarães e Ribeiro (2006), que Charles Miller trouxe também uma bomba de ar os uniformes e duas bolas da marca Shoot, fabricadas em Liverpool, além de um livro de regras, no qual Ihe permitia atuar como um verdadeiro missionário na divulgação do seu propósito, trabalhado também como árbitro nas partidas quando necessário, uma vez que conhecia muito as regras do esporte, vindo a falecer em 1.953 em São Paulo, onde nasceu. 
Voser; Guimarães e Ribeiro (2006), sugerem que no início as competições eram muito restritas e seletivas, praticado apenas pela elite paulistana e os funcionários de empresas inglesas sendo que os jogos aconteciam nos campos de rúgbi que existiam na época.

Foi em São Paulo e no Rio de Janeiros que surgiram os primeiros clubes no Brasil, mas, que na verdade praticavam outros esportes, preocupados mais com o social. Entre eles podemos citar o São Paulo Atlética Club, o Clube de Regatas Flamengo, fundado em 1.895, além do Clube de Regatas Vasco da Gama e Vitória da B.A fundados ambos em 1.898 .

No ano de 1.900, jovens amantes do futebol de origem alemã, inglesa e portuguesa teriam se juntado para criar um clube de futebol que seria mais tarde o Esporte Clube Rio Grande, no qual foi reconhecido pela CBF em 22 de julho de 1975 como o primeiro clube de futebol do Brasil, situado no Rio Grande do Sul. (VOSER; GUIMARAES; RIBEIRO, 2006).

\section{TENDÊNCIAS DE TREINAMENTO}

Com a evolução do futebol, após o seu surgimento, houve uma grande busca por novos métodos de treinamento que foram aperfeiçoados ao longo da história, sendo o sistema tático, de acordo com as características da equipe para implantação do sistema com seus princípios de jogo. (SILVA, 2008).

De acordo com Pivetti (2012), a fadiga periférica atinge o sistema nervoso central, podendo ser crônica, afetando assim a forma de pensar e agir, sendo mais acentuada do que a fadiga física, especialmente quando se treina em algo nível de concentração, a fim de selecionar o melhor repertório motor para solução das situações imprevisíveis que acontecem no jogo.

De acordo com a característica específica de cada esporte, havia a necessidade de uma evolução contínua nos processos de treinamento e construção de ferramentas de avaliação e monitoramento da progressão individual e coletiva do processo de 
treino, sendo que desta forma, começou ocorrer a busca pela especialização nas áreas da preparação física, tática, técnica, com a qualificação de treinadores e na área da fisiologia, etc. (LEITÃO, 2009).

Leitão (2009), afirma ainda que as alterações no processo de treino começaram a surgir na década de 50, onde era consenso entre os profissionais da área que as cargas oferecidas aos atletas, poderiam não ser suficientes para promover alterações metabólicas para melhores respostas agudas e crônicas ao processo de treinamento.

Todo o processo de treinamento está associado a ideia de jogo do treinador, e por consequência, a forma de treinar em razão do modelo de jogo, logo é possível que diferentes formas de treinar sejam praticadas em diferentes lugares do mundo, fazendo que novas tendências de treinamento sejam preconizadas. (LEITÃO, 2009).

Diante do exposto, chegamos a conclusão, que novas formas de se treinar principalmente as relacionadas a aspectos físicos, deveriam influenciar diretamente na forma de jogar da equipe, e que parecem ganhar força através de fundamentações teóricas.

Então começaram a surgir as tendências de treinamento com origem no Leste Europeu, depois surgiram os modelos de treinamento com origem no Norte da Europa e América do Norte, e por fim o modelo Latino de treinamento, mas nenhuma delas, se aproximou do modelo conhecido como Periodização Tática no futebol preconizado pelo professor Vitor Frade. (LEITÃO, 2009).

$\mathrm{Na}$ linha do tempo da periodização dos esportes coletivos, identificamos mudanças a partir do século XX, ocorrendo em três etapas sendo da sua origem até 1950, quando se inicia a sistematização do treinamento depois os períodos de 1950 a 1970, período esse de questionamentos, inquietações e dúvidas quanto aos modelos tradicionais de periodização e o período pós 1970 onde chegamos nos modelos contemporâneos de treinamento. (GOMES, 2009). 


\section{TENDÊNCIA DOS PAÍSES DO LESTE EUROPEU}

Para Silva (2008), a tendência do Leste Europeu, preconiza a divisão da época em períodos preparação ao treinamento com objetivos de se atingir um determinado platô de condicionamento físico, valorizando sobre tudo a vertente física, sem nenhuma preocupação com o modelo de jogo, dando ênfase a preparação física, desconectado com os coletivos, sendo extremamente um analítico a concepção do processo de treino.

Em que pese à concepção de Silva (2008), parecem ir de encontro a ideias de Matveev que entendia que o treinamento deveria ser dividido em épocas para se atingir picos de forma, com grande volume no início da preparação e pouca intensidade, invertendo-se as cargas no período competitivo, caracterizando o modelo clássico de treinamento.

Entretanto, Silva (2008) entende que o treino deve exacerbar um modelo de treinamento que contemple a forma de jogar que se busque, no caso em especificidade, sendo que qualquer outra forma de treinamento seria entendida como uma forma abstrata de treinar.

Fortes evidências indicam de acordo com Gomes (2009), que o modelo de treino do Leste Europeu, constituía um processo de treino mais analítico, voltado para o viés físico, buscando atingir picos de forma, não havendo preocupação, portanto com a forma de jogar, sendo um modelo desenvolvido para competições olímpicas onde se buscava um ou dois platôs de desempenho no ano. (GOMES, 2009).

Leve Pavlovtchi Matveev, cientista Russo, apresentou na década de 50 o modelo tradicional de treinamento, com base na teoria da Síndrome Geral da Adaptação.

Seu modelo de cargas era uma variação ondulante que ocorria nos treinamentos, nos quais eram divididos em três períodos: Preparatório, Período de competição e Período de transição. Ainda, o período preparatório divide-se em Geral e Específica. 
No período geral e especifico há uma predominância de grande volume e pouca intensidade, no entanto cabe ressaltar ainda, que essa preparação era base pincipalmente para esportes como natação, levantamento de peso e atletismo sendo que no período Específico ocorre grande ênfase no aperfeiçoamento da técnica e dá tática, além de prevalecer a intensidade em detrimento ao volume.

No período competitivo, o atleta deverá alcançar o pico de forma, estabilizando o volume e a intensidade. Já o período de transição, é quando o atleta se recupera físico e psicológico do esforço que realizou. (GOMES, 2009).

A variação do volume e da intensidade se expressa através de picos ondulatórios, respeitando sempre que os valores máximos de pico não coincidam no mesmo período, sendo os períodos preparatórios geral e específico com grande volume e período de intensidade máxima durante o período competitivo. (PANTALEÃO; ALVARENGA, 2008).

Figura1. Desenho com as ondulações da periodização clássica Manteve, (1997).

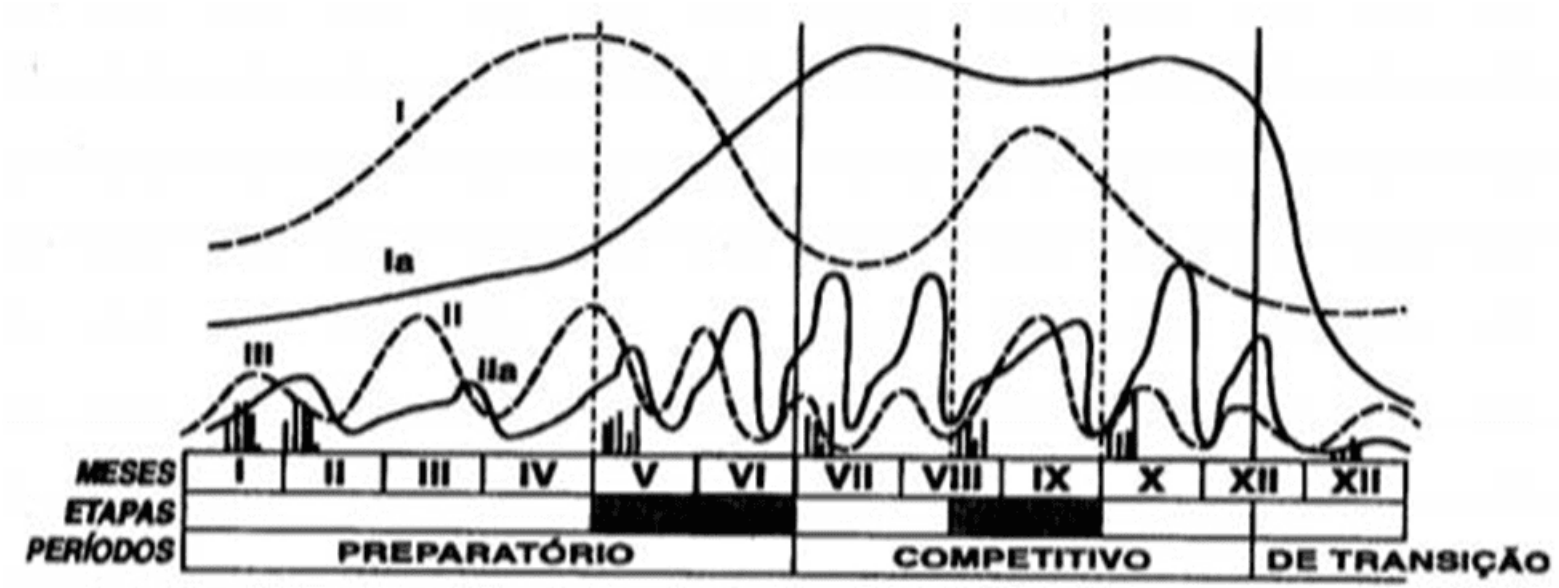

Volume (I, II, III)

Intensidade (la, II a)

Para que tenhamos êxito em qualquer modalidade, precisamos não só das capacidades especificas da modalidade bem desenvolvidas, mas sobretudo, 
precisamos de lastro, com nível geral elevado das capacidades funcionais do atleta bem desenvolvida já anteriormente. (FERREIRA, 2010).

Segundo Gomes (2009), não haveria possibilidade de um único modelo de periodização contemplar todas as modalidades esportivas, uma vez que devemos levar em consideração as características de cada esporte, que devem ser de alinhada a características dos atletas.

Gomez e Souza (2008), entendem ainda que o período preparatório no Brasil é muito curto, sendo em torno de um mês, chegando a conclusão que o modelo tradicional de Matveev não contempla a valências técnicas e táticas no futebol atualmente.

O treino deve ser específico para a modalidade, com exercícios que sejam trabalhados de acordo com os princípios de jogo, estando em consonância com o modelo de jogo, de acordo com a ideia de jogo do treinador. (FERREIRA 2010).

Fica evidente, portanto, que para os dias de hoje, a proposta de Matveev, parece não convergir em nada com a especificidade que o futebol preconiza.

\section{TENDÊNCIA DO NORTE EUROPEU E AMÉRICA DO NORTE}

A outra tendência de treinamento surgiu no Norte Europeu e América do Norte, diferente do modelo tradicional, mas longe do ideal para o futebol, deu grande importância ao desenvolvimento das capacidade funcionais especificas da competição, promoveu avaliação de cargas com testes físicos, buscando parâmetros para os jogadores, mas ainda voltado para o viés físico, técnico e psicológicos descontextualizados, sem conexão. (SILVA, 2008).

Depois da década de 50, questionamentos ao método de Matveev começaram a surgir, pois cientistas entendiam que era impossível um único modelo de cargas de treinamento contemplar todos os desportos, pois cada um possuía suas características e adaptações especificas a cada organismo de acordo com o esporte trabalhado. (GOMES, 2009). 
Caraveta (2009), afirma que essa tendência de treinamento era baseada na improvisação, e que os treinadores decidiam os conteúdos de treinamento, antes de iniciar a sessões, sendo que nos dias de treinos físicos, predominavam as maratonas de 08 a 12 quilômetros, e as arquibancadas eram utilizadas para subir e descer.

Exemplo de um modelo de treinamento tradicional semanal- Fragmentados anos 70 Rio Grande do Sul.

Tabela 1.

\begin{tabular}{|l|l|l|l|l|l|l|}
\hline Segunda & Terça & Quarta & Quinta & Sexta & Sábado & Domingo \\
Manha & Manha & Manha & Manha & Manha & Manha & Manha \\
\hline Folga 2 & Treino & Treino & Treino & Folga & Rachão & Folga \\
\hline & Fís. 1 & Fís. 3 & Fís.4 & & & \\
\hline Tarde & Tarde & Tarde & Tarde & Tarde & Tarde & Tarde \\
\hline Folga & Treino & Treino & Treino: & Treino & Folga & Jogo \\
\hline Fís.2 & Coletivo 5 & & Finalizações 6 & Coletivo 5 & & \\
\hline
\end{tabular}

Fonte: (Caraveta, 2009).

Treino Físico 1 =Maratona 08 a 12 km.

Treino Físico 2 = Folga + Piques .

Treino Físico 3 = Treino em circuito.

Treino Físico 4 = Treino Intervalado.

Treino Técnico 5 = Coletivo

Treino Técnico 6 = Finalizações

Leitão (2009), considera que o melhor desempenho nos esportes necessita de estímulos de treinamento adequado, com uma sequência lógica, estruturada, com 
aplicação progressiva de cargas, promovendo elevado desenvolvimento das capacidades funcionais para a modalidade específica.

Bompa (2010), ratifica que os exercícios adequados e específicos irão contribuir para elevado estado de funcionalidade do organismo dentro da modalidade praticada.

\section{SISTEMA DE TREINAMENTO EM BLOCOS}

Proposto pelo Prof. Dr. Yuri V. Verkhoshanski, através de um grande ciclo de adaptação (GCA), que compreende uma fase completa de desenvolvimento do organismo. (PANTALEÃO; ALVARENGA, 2008).

Figura 2. Modelo Geral do Sistema de Treinamento do CGA

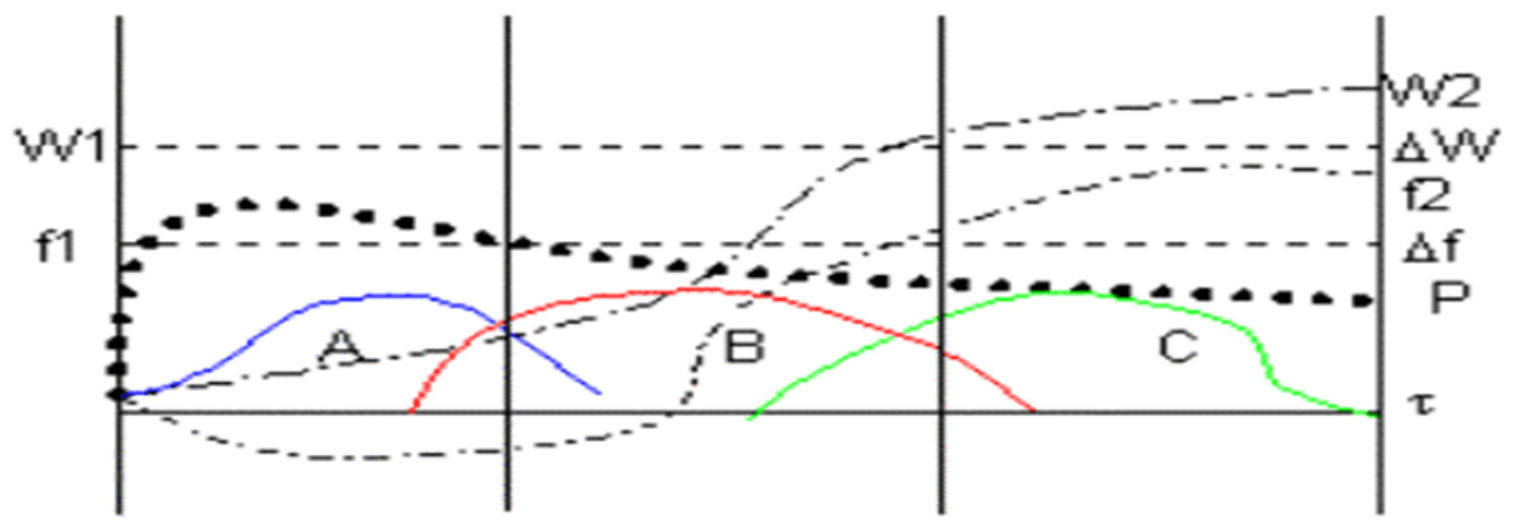

Fonte: (PANTALEÃO; ALVARENGA, 2008).

(A) Preparação Física Especial

(B) Preparação Técnico-Tática

(C) Etapa das Competições

O grande ciclo de adaptação, é dividido em três blocos (etapas) seguindo uma lógica: O bloco A ou de preparação física especial (Pfe) é o período específico de preparação para desenvolvimento das capacidades funcionais. O bloco B ou de preparação técnico-tática, tem como objetivo principal a assimilação das capacidades físicas e motoras, preparando para a competição. $\mathrm{O}$ bloco $\mathrm{C}$ ou etapa das competições prevê o ápice das capacidades no máximo de sua intensidade e desenvolvimento técnico, 
físico e tático, estando pronto para a competição. (PANTALEÃO; ALVARENGA, 2008).

\section{TENDENCIA LATINO AMERICANA}

A terceira tendência, é surgiu nos países latino americanos, busca a integração das capacidades físico e técnicas, mas ainda não se identifica ações que possam fazer parte da ideia de jogo de forma coletiva. Essa tendência é conhecida como treino integrado porque consegue se treinar com bola contemplando a dimensão física, mas longe ainda o contexto tático daquilo que se pretende. (LEITÃO, 2009).

Com o surgimento de uma nova tendência de treinamento, percebemos já um grande avanço nos métodos de treino, que começam a ser direcionados para a especificidade de cada modalidade, e no caso o futebol, tanto o gesto técnico, físico e tático, são trabalhados de forma integrada, ou seja, o treino com bola passa a fazer parte da rotina de treinamento, mas não de forma a contemplar o modelo de jogo, e todas as capacidades motoras devem ser trabalhadas desde o período preparatório, de forma especifica, ao contrário de que os modelos anteriores preconizavam.(LEITÃO, 2009)

O processo de organização e planejamento passou por profundas modificações entre os períodos da década de 1970 a 1980, levando a novos conceitos, onde o atleta passa a ser visto como um todo, e não em partes, necessitando assim de uma equipe multidisciplinar, a fim de dar suporte nas outras áreas como nutrição, fisioterapia, psicologia, com conteúdo e objetivos bem definidos. (GOMES; SOUZA, 2008).

\section{MODELO DE CARGAS SELETIVAS}

Antônio Carlos Gomes entendia que a periodização para o processo de treino precisava ser mais específica ao futebol, que apresenta um grande número de jogos, em torno de 70/80 por ano. (GOMES; SOUZA, 2008)

Na prática era estabelecido um ciclo anual de 52 semanas que será dividido em duas etapas, sendo caracterizada uma periodização dupla com duração de 26 semanas cada. (PANTALEÃO; ALVARENGA, 2008). 
A estruturação das cargas de treinamento proposta deve ser organizada de acordo com alguns fatores como número de sessões semanais, volume de treino na temporada também o total de horas sugeridas para a temporada. Ainda, é importante considerar o número de horas na semana, para melhor distribuição da periodização. (PANTALEÃO; ALVARENGA, 2008).

Nessa perspectiva, Gomes e Souza (2008), afirmam que o modelo de Cargas Seletivas parece ser mais apropriado para a modalidade futebol, pois devido ao grande número de jogos durante a temporada, e pouco tempo para preparação, muitas vezes menos de trinta dias, o levou a elaborar um modelo de distribuição de cargas, com pouca variação de volume durante o macro ciclo. No seu modelo ocorre uma alternância de treinamento das capacidades motoras a cada mês.

Durante o período competitivo, os trabalhos para as capacidades de força e velocidade, devem ser desenvolvidos juntos com a resistência especial, sendo que essas valências podem ser trabalhadas em campo reduzido, para o aprimoramento técnico, tático, sempre em alta intensidade, melhorando assim a velocidade. (GOMES; SOUZA, 2008).

Figura 3.

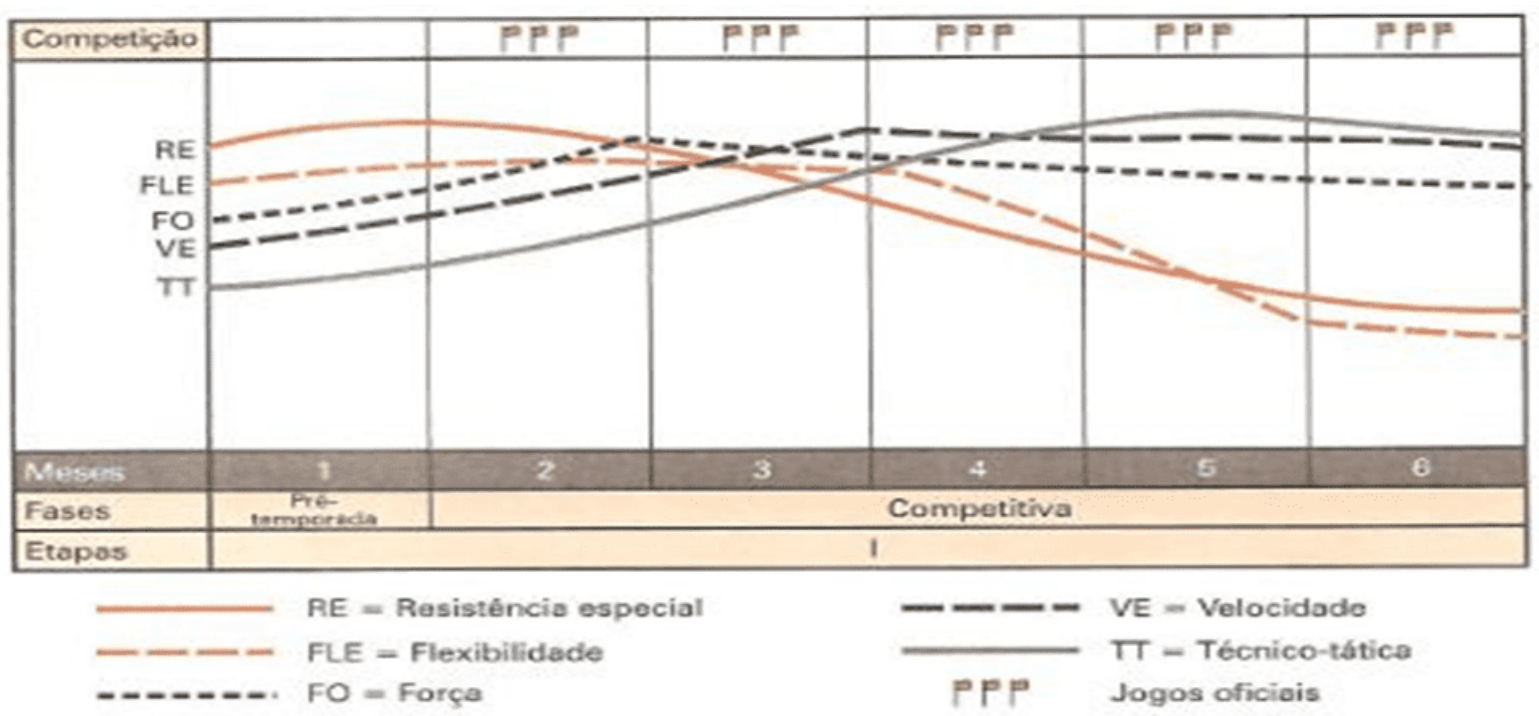

Fonte: (MORAES et al, 2016). 
De acordo com Moraes et al (2016) o modelo de Cargas Seletivas, proposto por Antônio Carlos Gomes, parece atender as necessidades do calendário do futebol brasileiro, que apresenta grande número de jogos, entre 75 e 85 jogos anuais sendo que esse modelo propõe um ciclo anual de 52 semanas dividido em dois microciclos de 26 semanas cada, caracterizando uma periodização dupla, e assim cada mês se trabalharia uma capacidade física, mas sempre com atenção especial a velocidade , sendo determinante para o aumento de desempenho.

Silva (2008, p.11), no entanto, afirma que pode existir outra forma de treinar, sendo o treino integrado ainda não especifico ao futebol.

Contrariado este caráter analítico, surge nos países nos países Latino Americanos, uma tendência designada, de "treino integrado" onde aspectos físicos, técnicos e táticos, São desenvolvidos conjuntamente. Deste modo, procura promover uma maior semelhança com a exigência da competição, conferindo uma grande importância ao jogo a sua especificidade. Contudo, esta concepção não deixa de ser abstrata, uma vez que se refere a um jogo geral a partir do qual se faz a estruturação do processo de treino.

Conforme estudos apontam, ocorreu um grande avanço, principalmente a partir da década de 70 e 80, nas metodologias de treinamento, aplicadas ao futebol, sendo, a tendência de treino Latino Americana, até o momento, a que mais se aproxima daquilo que buscamos como especificidade aplicado ao futebol.

Lopez (2005), ressalva, em entrevista ao jornal "O Jogo", o treinado português Carvalhal ao se referir ao modelo integrado e sistêmico, diz que no modelo integrado, a bola faz parte do treino, mas não como deveria, de acordo com o modelo de jogo, já no modelo sistêmico, a bola faz parte do treino já no primeiro dia, adaptando o jogador ao processo de treino físico, técnico e tático, tudo junto e não separado.

\section{TENDÊNCIA PORTUGUESA - PERIODIAZAÇÃO TÁTICA}

A última tendência a ser analisada, oriunda de Portugal, criada pelo Professor Vitor Frade, na década de 90 e aplicada por treinadores consagrados como José Mourinho, 
e Pepe Guardiola, além de ser adotada como modelo orientador do processo de treino europeu ficou conhecida como Periodização Tática. (SILVA, 2008).

Silva (2008), afirma que a Periodização Tática, tem como componente principal, a operacionalização do processo de treino, através da modelação associada ao modelo de jogo, de acordo com os princípios de jogo, que devem ser trabalhados conforme a ideia de jogo do treinador.

Percebe-se a evolução quanto ao avanço das tendências de treinos desenvolvidas em várias partes do mundo, evidenciam, e sinalizam com uma nova forma de treinar, finalmente direcionada para o Modelo de Jogo e seus princípios que devem ser operacionalizados, direcionando para o verdadeiro treino específico para a modalidade futebol.

Silva (2008), afirma ainda que a Periodização Tática, regula todo o processo de treino, que nesse modelo se desenvolvem as variáveis físicas, técnicas e psicológicas também, e o processo de treino tem como grande objetivo a aquisição de conceitos de jogo, baseados nos princípios de jogo, sendo, portanto um treino específico para aquilo que se deseja para a equipe.

Parece ser a Periodização Tática, a metodologia de treino que venha a romper com outras formas de treinar e conceber uma forma de jogar que seja operacionalizada a partir do treinamento sistemático, produzindo padrões de comportamentos individuais, setoriais, inter setoriais e coletivos.

A Periodização Tática, concebe o treino como um processo de aprendizagem de forma didática, baseado nos conceitos e princípios dessa forma de treinar, rompendo definitivamente com o modelo convencional de treinar, tudo baseado em conceitos preconizados pela ciência. (PIVETI, 2012). 
Figura 4. Morfociclo padrão desenvolvido por Mourinho.

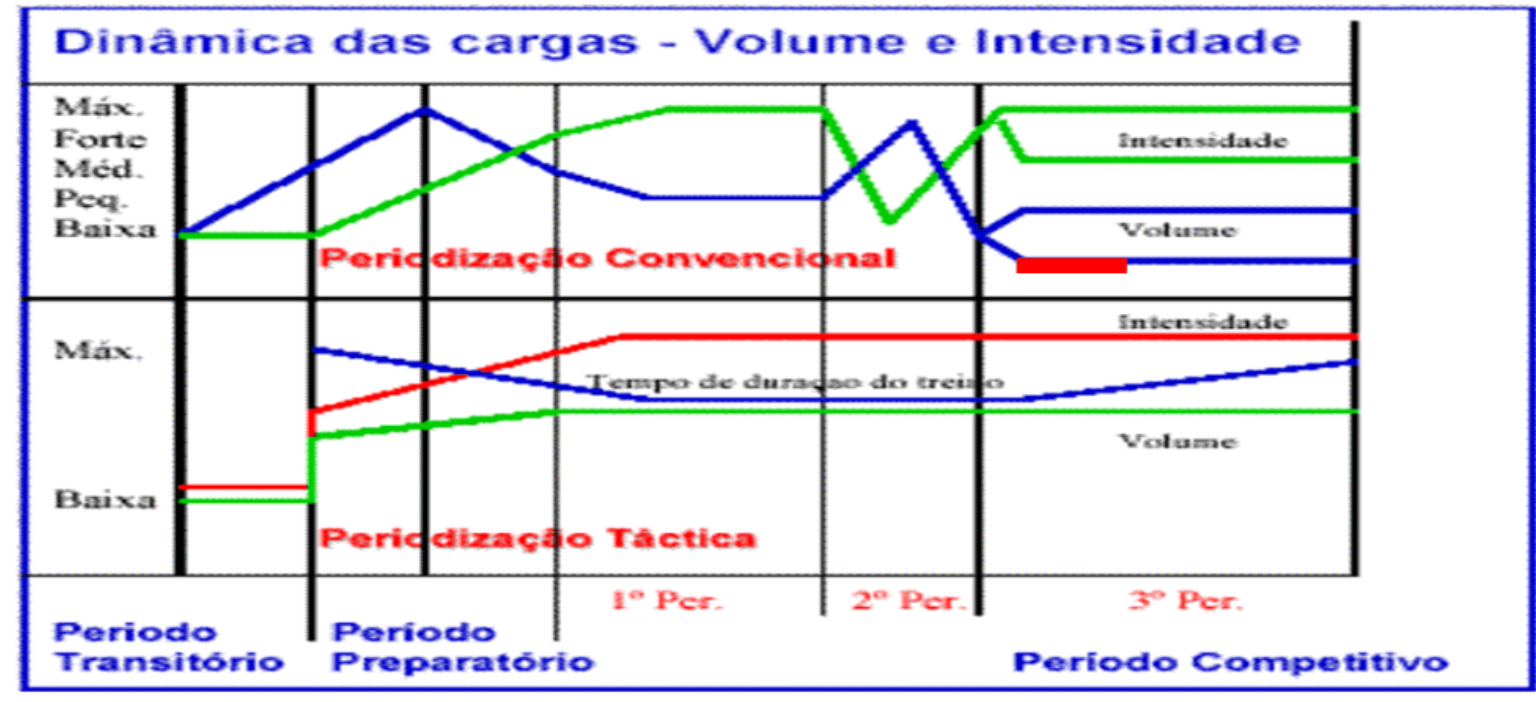

\section{Periodização convencional:}

1. Volume:

2. Intensidade:

\section{Periodização Tática:}

1. Volume:

2. Tempo de duração do treino:

3. Intensidade:

Fonte: (OLIVEIRA, 2005).

De acordo com Pivetti (2012), o padrão de comportamento que se espera emergir, devem ser baseados nos princípios de jogo, em diversas dimensões revelando uma intencionalidade a partir de padrões de comportamentos, que irão servir como a identidade da equipe sendo revelado em cada momento do jogo.

Para se chegar ao modelo de jogo que se espera, é preciso selecionar cuidadosamente os exercícios, fazendo emergir assim os princípios de jogo que são praticados durante o treino, revelando um padrão de comportamento coletivo que se pretende. (FERREIRA, 2010). 


\section{RESULTADOS E DISCUSSÃO}

1.894 - Oficialmente ficou estabelecida a entrada do futebol, de acordo com regras do Football Associativo, como elemento integrante da cultura corporal de movimento do Brasil, quando Charles William Miller (1874-1953), brasileiro de descendência inglesa, volta de seus estudos na Inglaterra, nesse mesmo ano, e traz consigo uma bola de futebol e alguns uniformes para a prática do jogo, transformando-se no grande incentivador do futebol na capital paulista (OLIVEIRA; COLPAS 2014).

Assim ao retornar para São Paulo, trouxe duas bolas de futebol da marca Shoot, confeccionadas em Liverpool, uma bomba de ar, dois uniformes para jogar, além de um livro grosso que continham as regras de futebol da época. Miller, então como um missionário, começa a divulgar o esporte para os ingleses que viviam em São Paulo. Conforme a literatura, Miller, era habilidoso, e dominava todas as regras, atuando inclusive como árbitro em algumas partidas. Faleceu em 1.953, no mesmo lugar em que nasceu (VOSER, GUIMARAES, RIBEIRO, 2006).

De acordo com Leitão, (2009), foi a partir da década de 50 que a preparação entre os profissionais do futebol começou a sofrer alterações, chegando à conclusão que a maneira como treinavam, não eram suficientes para para respostas adaptativas ao futebol.

A partir do século XX, a periodização do treinamento desportivo sofreu transformações em diversos esportes. Entretanto, podemos citar três etapas que ocorreram na história dos modelos de planejamento desportivo:

Da sua origem até 1950, quando se inicia a sistematização do treinamento, depois de 1950 até 1970, começam a surgir questionamentos quanto aos modelos clássicos de periodização e com isso surgem novas propostas, e de 1970 até os dias de hoje, em que se vive uma grande evolução dos conhecimentos. (GOMES, 2009).

Porém, o divisor de águas no processo de treinamento tem origem em Portugal, com a Periodização tática, criada pelo Professor Vitor Frade, na década de 90 e aplicada 
por treinadores consagrados como José Mourinho, e Pepe Guardiola, além de ser adotada como modelo orientador do processo de treino europeu ficou conhecida como Periodização Tática. (SILVA, 2008).

A denominada Periodização Tática, é uma concepção de treino e competição para o futebol que tem sido preconizada pelo Vitor Frade. Nesse modelo de treino o processo de preparação deve centrar-se na operacionalização de um jogar, através da criação continua de um Modelo de Jogo, e os seus princípios de jogo. (SILVA, 2008).

Com base em evidências, verificamos formas distintas de conceber o processo de treinamento ao longo da história, sendo a metodologias conhecida como periodização tática a que mais reúne pressupostos teóricos para conceber o treino, sendo a forma de treinar preferida pelo técnico José Mourinho.

Oliveira, Ferreira, (2010) afirmam que treinar em especificidade, é conceber exercícios que permitam exacerbar os princípios de jogo, de acordo como o modelo de jogo.

\section{METODOLOGIA}

Foi realizada de uma revisão bibliográfica, em que foram pesquisadas diversas obras literárias. As pesquisas foram realizadas somente em português, em base de dados como Scielo, Google acadêmicos, e periódicos além de livros especializados relacionados à temática futebol. A pesquisa foi realizada entre os meses de março a agosto de 2019.

\section{CONSIDERAÇÕES FINAIS}

Com base na literatura, encontramos diversos achados sinalizando que realmente foi Charles Miller que trouxe para o Brasil o conhecimento e disseminação do futebol no Brasil,

Ficando definido oficialmente em 1.894 a chegada do futebol no Brasil, se tornando elemento integrante da cultura corporal de movimento do Brasil. 
Charles William Miller, brasileiro de descendência inglesa, retornou da Inglaterra após a conclusão dos seus estudos, trazendo consigo uma bola de futebol, uniformes e um livro de regras.

Diante disso, após robustas evidencias quanto ao surgimento do futebol no Brasil, na qual se deu através de Charles Miller ao voltar da Inglaterra, verificamos ao longo da história um grande avanço nas metodologias de treinamento físico, técnico e táticos, sendo a periodização tática, a que parece atender mais especificamente as necessidades do futebol.

A Periodização Táctica parece transcender a fragmentação reducionista da teoria Convencional e superar o holismo abstracto do Treino Integrado para evidenciar uma nova forma de ver o jogo.

Com base em evidências, são inegáveis as contribuições científicas ao longo da história para o avanço das metodologias de treinamento, cada uma em sua época, especialmente do cientista Russo, Dro- Professor emérito Leve Pavlovtchi Matveev. Em momento algum tivemos pretensão de determinar qual a melhor forma de treinar, pois métodos nos indicam caminhos que devemos seguir, sempre fundamentados em bases teóricas para que possamos diminuir a margem de erros.

Por fim, entendemos que o processo de treinamento é um ato contínuo e inacabado, suscetível a erros e acertos, o que nos deixa inquietos, para prosseguimos aplicando nossas metodologias de trabalho, fundamentado em estudos que venham contribuir de forma significativa com nosso crescimento.

Sugerimos novos estudos na área do futebol, a fim de continuar o universo fascinante do futebol e da Periodização tática como metodologia de treinamento, rompendo definitivamente com os processos de treinos pouco específicos a modalidade coletiva que é o futebol. 


\section{REFERÊNCIAS}

CARAVETA, ELIO. O Enigma da Preparação Física no Futebol. Porto Alegre, RS. Editora A.G.E. 2009. p.23-24-25.

FERREIRA, FRANCISCO.ADOLFO. Uma visão holística do futebol. Universidade do Futebol. São Paulo: Disponível em <http://universidadedofutebol.com.br/uma-visao-holistica-do-futebol/>Acesso em 03 mar. 2017.

FERREIRA, FONTES.DIOGO. A importância de um Modelo de Jogo no Futebol: A especificidade vista como um veículo catalizador no processo de treino. Dissertação de Mestrado. Faculdade de Desporto de Educação Física. Universidade do Porto: 2010 p.p. 7-11-12- 28-52.

GOMES, ANTONIO.CARLOS. Treinamento desportivo: Estruturação e Periodização. $2^{\circ}$-Ed. Porto Alegre: Artmed.2009. p.p. 209-210-212.

GOMES, ANTONIO.CARLOS; SOUZA, J. Futebol: Treinamento desportivo de alto rendimento. Ed. Artmed. Porto Alegre: 2008. p.p. 209 - 237- 338- 240.

LEITÃO, RODRIGO, APARECIDO. AZEVEDO. O jogo de futebol: investigação de sua estrutura, de seus modelos e da inteligência de jogo, do ponto de vista da complexidade: Tese de Doutorado. Campinas, S.P: 2009 p.p.58-59-60.

LOPEZ, MIGUEL.AUGUSTO. DIAS. A construção de um futebol: Que preocupações numa relação treino hábito dentro de uma lógica Periodização Tática: Modelação Sistêmica. Dissertação de Graduação. Faculdade de Ciência e Desporto da Educação Física. Portugal: .2005. p.35.

MORAES, MARCOS.SANTOS, RODRIGO.BECKEMKAMP, DAIANA. BURGOS, LEANDRO.TIBIRIÇA. Modelos de periodização do treinamento e o calendário competitivo das equipes de elite do futebol brasileiro. Santa Cruz do 
SUL: 2014. Disponível em.< http://www.efdeportes.com/efd197/modelos-deperiodizacao-do-treinamento-e-futebol.htm> Acesso em 02 fev.2018.

OLIVEIRA, FLÁVIO. ISMAEL. SILVA. COLPAS, RICARDO. DUCATTI. Futebol: Origem e História. Claretiano, Batatais: S.P. 2014: p.39 - 40.

OLIVEIRA, RAÚL. A planificação, programação e periodização do treino em futebol. Um olhar sobre a especificidade do jogo de futebol. 2005.Portugal:Disponível em: <http://www.efdeportes.com/efd89/futeb.htm>Acesso em 08 fev.2017.

PANTALEÃO, DIOGO; ALVARENGA, RENATO.LUIS. Análise de modelos de periodização para o futebol. Rio de Janeiro: 2008. Disponível em: $<$ http://www.efdeportes.com/efd119/analise-de-modelos-de-periodizacao-para-ofutebol.htm> Acesso em 04 fev. 2017.

PIVETTI, BRUNO. MARQUES.FERNANDES. Periodização Tática: 0 futebol arte alicerçado em critérios. São Paulo: Ed. Forte. 2012. p.p.46 -50- 199.

SILVA, MARISA. O desenvolvimento do jogar segundo a periodização tática: Coleção preparação futebolística. Ed. MC Sports. Espanha:2008. p.p.11-12.

VOSER, ROGÉRIO. CUNHA. GUIMARÃES, MARCUS.GEOVANE. V; RIBEIRO, EVERTON. Futebol: História, Técnica e Treinamento de goleiros Porto Alegrete: p.p.16-17-18-19. 2006. EDIPUCS.

Enviado: Agosto, 2020.

Aprovado: Setembro, 2020. 